\title{
Prostate Carcinoma Metastatic in the Lung
}

National Cancer Institute

\section{Source}

National Cancer Institute. Prostate Carcinoma Metastatic in the Lung. NCI Thesaurus.

Code C36307.

A carcinoma that arises from the prostate gland and has spread to the lungs. 